\title{
Effect of Individualized Pain Management on Periopera- tive Pain Control of Traumatic Orthopedic Patients
}

\author{
L. GUO, X. ZHOU1 AND L. WANG ${ }^{*}$
}

Department of Orthopedics, Shaoxing City Keqiao District Hospital of Traditional Chinese Medicine, Shaoxing 312030, ${ }^{1}$ Department of Rehabilitation Medicine, The Affiliated Huai'an Hospital of Xuzhou Medical University and The Second People's Hospital of Huai'an, Huai'an 223002, '2Department of Rehabilitation Medicine, Lianshui County People's Hospital, Huai'an 223400, China

\section{Guo et al.: Pain Management of Traumatic Orthopedic Patients}

\begin{abstract}
It is important to take active and effective nursing management initiatives for perioperative pain control of traumatic orthopedic patients. In this study, individualized pain management program was applied to perioperative pain control of traumatic orthopedic patients and the application effect was observed. In this study, 1200 traumatic patients treated in orthopedics department of our hospital from June 2012 to June 2016 were selected as research objects. All patients were given the right to know and randomized. Conventional pain management initiatives were applied to 600 patients in the reference group, while individualized pain management was applied to 600 patients in the study group. After pain management in different ways, effect of perioperative pain control of the two groups was observed and compared. There was no significant difference in visual analogue scale scores of the two groups before implementation of pain management, that is, $p$ value is greater than 0.05 . After implementation of different pain management, visual analogue scale score of the study group with individualized pain management is significantly superior to the reference group with conventional pain management, the difference is statistically significant $(p<0.05)$. In comparison of pain control satisfaction of the two groups, the results show that overall satisfaction

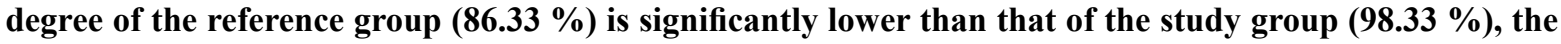
difference is statistically significant $(\mathbf{p}<\mathbf{0 . 0 5})$. Individualized pain management of traumatic orthopedic patients can significantly improve and control degree of pain during perioperative period and promote patients rehabilitation process by improving their comfort. Moreover, it can provide patients with high quality management services, receive broad satisfaction, improve harmony between nurse and patient. Therefore, individualized pain management initiatives are worthy of wide popularization and application in clinical practice.
\end{abstract}

Key words: Traumatic orthopedic patients, individualized pain management, perioperative period, pain control

Patients treated in traumatic orthopedics usually have fractures of the limbs. In clinics, surgery is the preferred treatment option for such patients. Patients in the perioperative period often have varying degrees of pain which brings heavy physical and psychological burden and stress to patients on the one hand and easily causes other complications on the other hand, thereby hindering the treatment efficacy, reducing patients quality of life, extending their rehabilitation ${ }^{[1]}$. There are many factors leading to orthopedic injuries, such as traffic accidents, fall from a height, violent impact and so on. There are more than 30 clinical typical cases of traumatic orthopedics, the most common of which is fracture of tibial plateau (fig. 1). Corresponding pain management after surgery can effectively control and reduce pain degree, so that patient comfort improves. Individualized pain management is a new type of pain management adapted to development needs of current medical treatment, which can give play to ideal pain control effect ${ }^{[2-5]}$. This study explores the effect of individualized pain management in perioperative pain control of traumatic orthopedic patients in a grouped manner. In this study, 1200 traumatic patients treated in orthopedics department of our hospital from June 2012 to June 2016 were selected as research objects. All the patients were diagnosed by X-ray and computed

*Address for correspondence

E-mail: zsg_yf@163.com 
tomography before operation. There was no patient with severe cardiopulmonary and renal dysfunction, mental disorder, drug allergy history, etc., with good therapeutic compliance. All patients had the right to know and were randomized with consent into study group and reference group, respectively with 600 cases. The study group consisted of 388 males and 212 females ranging in age from 20 to $76 \mathrm{y}$, $(48.6 \pm 1.2 \mathrm{y})$ in average; the reference group consisted of 402 males and 198 females ranging in age from 18 to $75 \mathrm{y},(49.7 \pm 2.3$ y) in average. Fractures of the patients: 78 cases of humeral shaft fracture, 82 cases of fracture of distal radius, 45 cases of femoral neck fracture, 68 cases of double forearm fracture, 105 cases of intertrochanteric fracture, 96 cases of tibial fracture, 52 cases of femoral shaft fracture and 74 cases of surgical neck fracture of the humerus. There is comparability in general data of the study group and the reference group, that is, $\mathrm{p}$ value is greater than 0.05 . The 600 patients in the control group were treated with conventional pain management, which means that medical staff has active and effective communication with the patient to grasp the pain status, guide the correct way of relieving. Meanwhile, proper indoor temperature and air circulation should be ensured and strong light stimulation, etc. should be avoided. Based on the patients actual situation, correct analgesic drugs should be applied according to the different stages and the doctor's advice. Individualized pain management was performed on the 600 patients in the study group, including the following contents: within $6 \mathrm{~h}$ after the patient's entry into the hospital, the relevant members

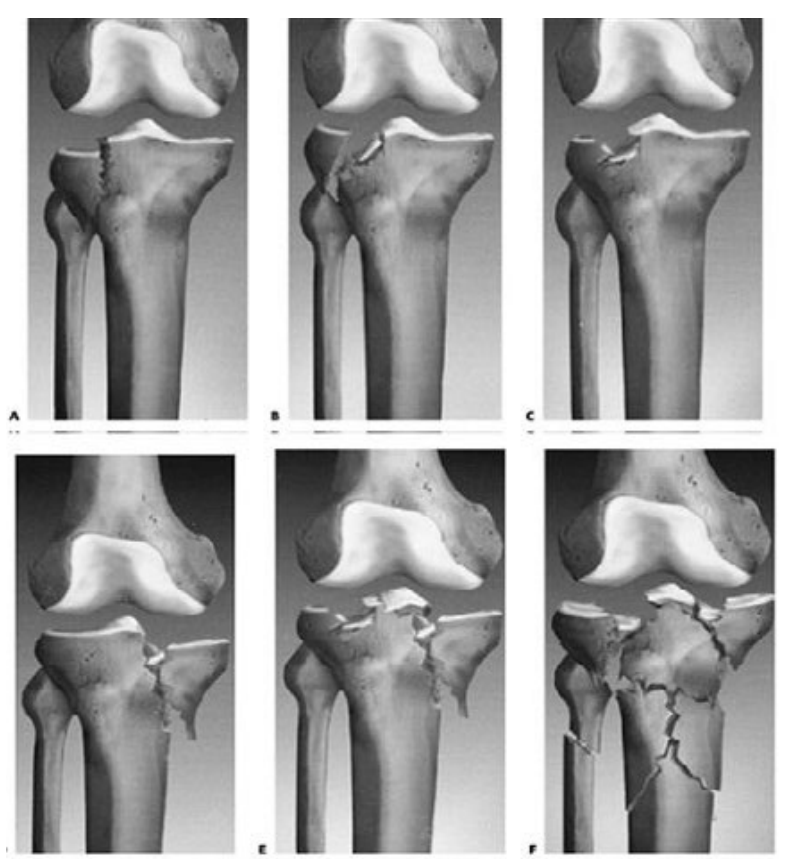

Fig. 1: Fracture of tibial plateau 219 of the management team (caregiver, physician anesthetist, etc.) closely evaluated the patient's pain perception, age, weight, pain history, history of surgery and drug allergy, mental state; developed targeted, individualized pain knowledge education based on the assessment results and guided the patient in pain scoring; management team physicians should closely improve the examination, give careful assessment of the patient's trauma degree, develop individualized analgesic program for the patient based on time, scope of surgery, examination and assessment results, provide active step by step analgesic therapy. The analgesic regimen includes name, dosage of analgesic drugs used before and after surgery, route and time of administration, analgesia during the surgery is mainly responsible by the anesthesiologist. During the analgesia program, nurses should also provide patients with psychological counseling and non-drug intervention, record and provide timely feedback of analgesia effect ${ }^{[6]}$. During this period, if pain management is not ideal, timely adjustment and replacement of analgesic program is needed. After pain management in different ways, degree of pain and pain management satisfaction of the two groups were compared. Visual analogue scale (VAS) was used to evaluate the patient's pain, which consisted of four criteria: painlessness, mild pain, moderate pain and severe pain. Scored between 0 points to 10 points, 0 point means painlessness, $1-3$ points mean mild pain, 4-6 points mean moderate pain, 7-10 points mean severe pain $^{[7]}$. The hospital-made pain management satisfaction questionnaire was used for statistics of management satisfaction, which included such contents as management skills, hospital environment, service attitude, etc. The highest score is 100 points $^{[8-12]}$. The 85 points or more suggest great satisfaction, 60-85 points suggest satisfaction and less than 60 points suggest no satisfaction. In this study, SPSS 21.0statistical softwarewasemployedfordataprocessing. Count data are expressed as (n, \%) and measurement data are expressed as $(\overline{\mathrm{x}} \pm \mathrm{s})$, respectively tested by chi square and $t$. In the presence of statistical significance in difference, $p$ value is less than 0.05 . As shown in Table 1 , there is no statistically significant difference ( $p>0.05$ ) between the two groups in degree of pain before and after pain management. After implementation of different pain management programs, VAS score of the study group significantly decreased on the $3^{\text {rd }}$ and $7^{\text {th }} \mathrm{d}$. There is statistical significance $(\mathrm{p}<0.05)$ compared with the reference group. As shown in Table 2 below, pain management satisfaction of the study group $(98.33 \%)$ is significantly superior to that of the Indian Journal of Pharmaceutical Sciences 
control group $(86.33 \%)$, the difference is statistically significant $(p<0.05)$. Traumatic orthopedics is one of the main clinical departments. Its common cases include open calcaneal fracture (fig. 2), humeral fracture of the ankle (fig. 3), etc. There will be varying degrees of pain after surgery, which not only affects patient's treatment compliance, but also reduces prognostic effect. A large number of clinical practice experiences prove that significant results can be achieved by applying individualized pain management in perioperative pain management of traumatic orthopedic patients. Establishment of a special pain management team to make relevant pain assessment after patients admission, develop scientific, targeted, individualized analgesia

TABLE 1: COMPARISON OF DEGREE OF PAIN OF THE TWO GROUPS ( $\overline{\mathbf{x}} \pm \mathbf{s})$

\begin{tabular}{lcccc}
\hline Group & Case number & $\begin{array}{c}\text { Before pain } \\
\text { management }\end{array}$ & $\begin{array}{c}\text { The } 3^{\text {rd } d \text { of pain }} \\
\text { management }\end{array}$ & $\begin{array}{c}\text { The } 7^{\text {th }} \mathrm{d} \text { of pain } \\
\text { management }\end{array}$ \\
\hline Study group & 600 & $7.56 \pm 0.19$ & $3.54 \pm 0.15$ & $1.34 \pm 0.06$ \\
Reference group & 600 & $7.48 \pm 1.62$ & $5.89 \pm 0.66$ & $3.46 \pm 0.47$ \\
$\mathrm{t}$ & & 0.86 & 2.35 & 6.62 \\
$\mathrm{p}$ & & $>0.05$ & $>0.05$ & $>0.05$ \\
\hline
\end{tabular}

TABLE 2: COMPARISON OF PAIN MANAGEMENT SATISFACTION OF THE TWO GROUPS [n (\%)]

\begin{tabular}{lccccc}
\hline Group & Case number & Great satisfaction & Satisfaction & No satisfaction & Overall satisfaction \\
\hline Study group & 600 & $456(76.00)$ & $134(22.33)$ & $10(1.67)$ & $590(98.33)$ \\
Reference group & 600 & $280(46.67)$ & $238(39.67)$ & $82(13.67)$ & $518(86.33)$ \\
$x^{2}$ & & & & & 7.63 \\
$\mathrm{p}$ & & & & & $<0.05$ \\
\hline
\end{tabular}

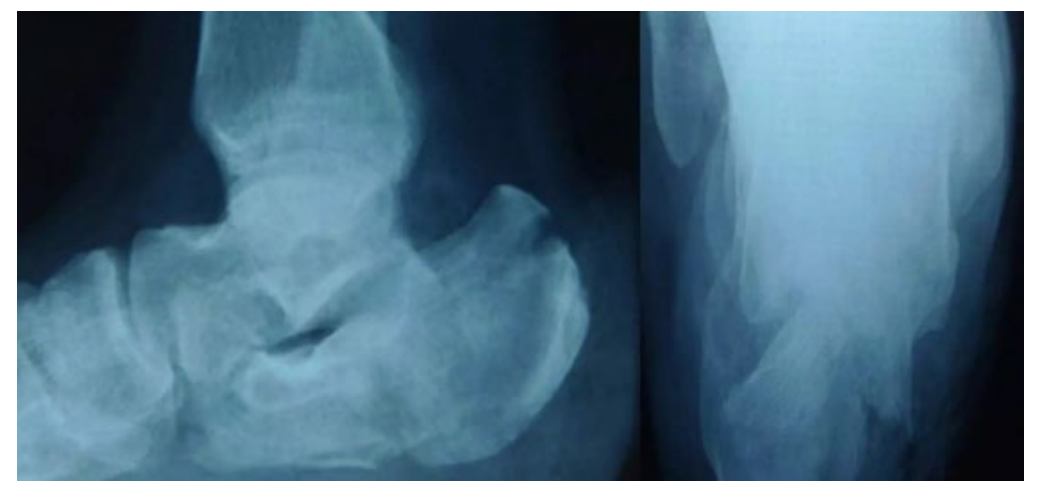

Fig. 2: Open calcaneal fracture

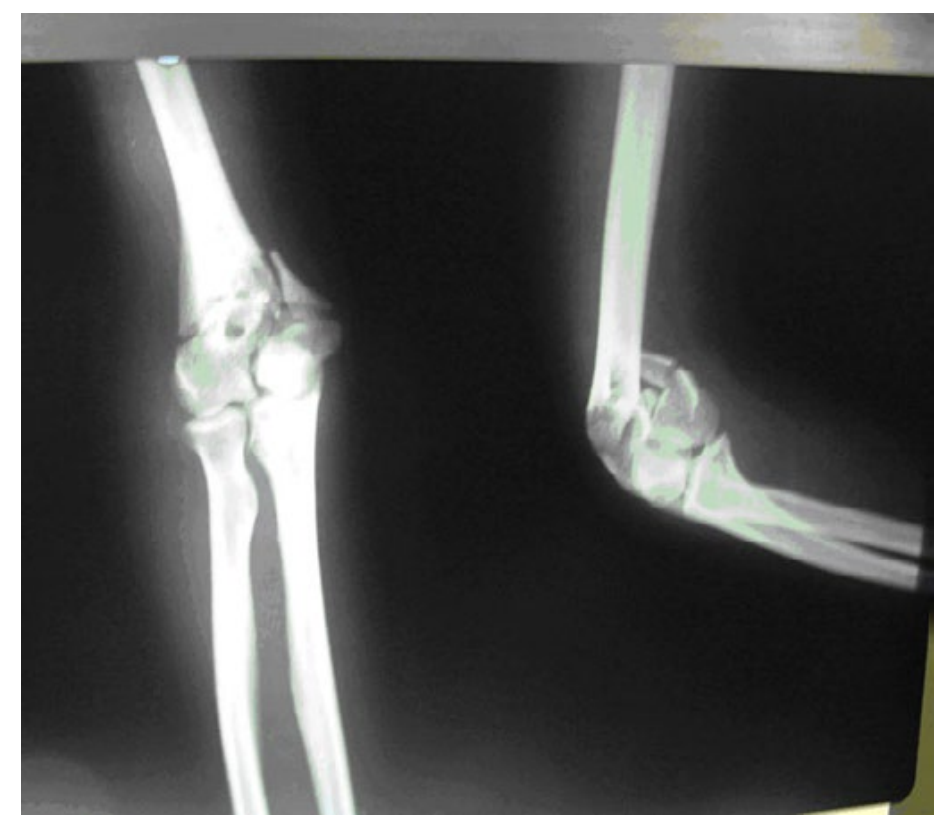


program based on patients actual situation plus intraoperative analgesia by excellent anesthesiologist in the hospital, truly realizes complete perioperative analgesia, provides quality services to patients, so that they feel more comfortable with rehabilitation accelerated. In the established pain management team, nurses and physicians, anesthesiologists have years of work experiences. During operation, they not only provide single form of analgesia, but take patients as the center, conduct related work according to the patient's actual situation. Moreover, in pain education, disease related knowledge, pain treatment methods, effects, etc., are introduced to patients, which enhance the patient's attention and trust in health care workers, so that treatment enthusiasm is improved. In summary, individualized initiatives of perioperative pain management of traumatic orthopedic patients can significantly reduce the pain, improve treatment safety and comfort and ensure that patients can have good treatment compliance, promote harmonious development of nurse-patient relationship, thereby shortening hospital stay, promoting patients rehabilitation as soon as possible.

\section{Acknowledgements:}

These authors contributed equally to this work.

\section{Conflicts of Interest:}

The authors declared no conflict of interest.

\section{REFERENCES}

1. Ling GD. The influence of individualized pain management on the perioperative pain of orthopedic trauma patients. Shenzhen J Integr Tradit Chin West Med 2016;12(15):27-9.

2. Peng L, Huang TW, Xiao P, Chen XL, Liu QL, Gui ZZ, et al. Analysis of satisfaction and influencing factors of postoperative pain management in orthopedic trauma patients. Today Nurse 2014;14(11):148-50.

3. Wiznia DH, Zaki T, Leslie MP, Halaszynski TM. Complexities of perioperative pain management in orthopedic trauma. Curr Pain Headache Rep 2018;22(9):1-9.

4. Song YQ, Zeng H. Effect of individualized pain management on perioperative pain in patients undergoing hip replacement. Med Clin Res 2014;4:751-3.

5. Taylor DM, Johnson OG, Lee M, Ding JL, Ashok A. The effect of provision of pain management advice on patient satisfaction with their pain management: a pilot, randomised, controlled trial (pain advice trial). Emerg Med J 2016;33(7):453-7.

6. Zhang Q. Effect of individualized pain management on perioperative pain control of traumatic orthopedic patients. Chin Health Stand Manag 2015;22(5):25-6.

7. $\mathrm{Xu}$ HC. Measures and effects of individualized pain management in department of traumatology and orthopedics. J Tradit Chin Med Manag 2015;23(20):57-8.

8. He Y. Effect of individualized pain management on perioperative pain control of orthopedic patients. Everyone Well 2016;11(8):121.

9. Chen CL, Zeng Y. Application of individual pain management in perioperative period of trauma department of orthopedics. Chin Community Doct 2018;34(30):87-8.

10. Aasa B, Berglund L, Michaelson P, Aasa U. Individualized low-load motor control exercises and education versus a highload lifting exercise and education to improve activity, pain intensity and physical performance in patients with low back pain: A randomized controlled trial. J Orthop Sports Phys Ther 2015;45(2):77-85.

11. Zhang ZL, Yu P, Xu J, Lv XQ. The implementation effect of individualized pain management model in customers. J Tradit Chin Med Manag 2018;26(1):40-2.

12. Hou LL, Wang J, Liao P, Li T. The influence of individualized pain management on the perioperative pain control of orthopedic trauma patients. J Nurse Train 2012;27(16):14771478.

This is an open access article distributed under the terms of the Creative Commons Attribution-NonCommercial-ShareAlike 3.0 License, which allows others to remix, tweak, and build upon the work non-commercially, as long as the author is credited and the new creations are licensed under the identical terms

This article was originally published in a special issue, "Evolutionary Strategies in Biomedical Research and Pharmaceutical Sciences" Indian J Pharm Sci 2021:83(3) Spl issue;218-221 